\title{
Experimental investigation of pultruded GFRP connections
}

\author{
Daler Aripov ${ }^{10000-0002-5912-9672]}$, Ivan Kuznetsov ${ }^{10000-0001-6838-0319]}$, and Marat \\ Salakhutdinov ${ }^{1 *[}$ 0000-0002-9452-0271] \\ ${ }^{1}$ Kazan State University of Architecture and Engineering, 420043, Zelenaya st., Kazan, Russia
}

\begin{abstract}
At present, design and construction of all-FRP structures with the use of GFRP are developing. All-FRP frame structures use bolted connections to form nodes between the elements, particularly steel bolts. This research focuses on the use of FRP pultruded plates instead of chords and webs. Frame construction nodes are formed by adjoining frame elements at different angles to the chords through gusset plates. In accordance with the literature analysis, a small number of tests have been carried out to investigate connections at angles to the pultrusion direction the pultrusion direction. Both experimental and numerical studies made with pultruded plates and L-shape FRP profiles have demonstrated that the plates have considerable influence on the strength and deformation of joints so that the joints failure mode involves mainly the bolted plate. These results were then compared against numerical predictions obtained using Ansys for finite-element analysis.
\end{abstract}

Keywords: pultruded FRP, connection, stress, deformation, construction.

\section{Introduction}

In recent years, fiber-reinforced polymer (FRP) composites have emerged as an interesting construction material in the civil sector, mainly because of their high strength-to-weight and stiffness-to-weight ratios, corrosion resistance, high durability, and high adaptability to different contexts and design needs [1-3]. They are interesting for the renewal of existing structures, especially in the rehabilitation of concrete structures such as buildings or bridges, and for new construction [4].

In addition to the consolidated use of FRP composites, a growing new technology is the design of all-FRP construction by means of structural pultruded profiles [5]. Due to its mechanical properties, glass fiber-reinforced polymer (GFRP) is an alternative to conventional construction materials such as steel or wood [6-7]. The most widely known applications of GFRP are foot and road bridges [8-10], temporary and emergency framed structures [11], and independent lightweight structures in existing buildings [12-13]. However, all-GFRP construction is limited by its structural joints, which represent structural discontinuities associated with stress localization [14].

* Corresponding author: architector-1992@mail.ru 
Structural joints can be bonded or bolted nevertheless; they often represent a gap in structural behaviour because of their failure mode [15]. Typically, bolted chord-to-web joints are formed using gusset plates, GRP bolts, and, more frequently, steel bolts. The behaviour of bolted connections between composite profiles and gusset plates is influenced by factors such as high-stress concentrations near bolt holes, no yielding capability, and reduced strength due to cleavage, net tension, shear-out, and bearing-mode failures [16-17]. Over the last two decades, many studies have been devoted to the operation of FRP element nodes connected at right angles (beam-to-column joints) [18-20]. Experimental tests show that initial joint stiffness is determined by the stiffness of the connecting components. Frame construction nodes are formed by adjoining frame elements at different angles to the chords through gusset plates. In accordance with the literature analysis, a small number of tests have been carried out to investigate connections at angles to the pultrusion direction. Existing design solutions of gusset plates in FRP frame structures are mainly made of steel or composite material produced using other technologies.

This paper focuses on experimental and numerical studies of innovative chord-to-web joints connecting two L-shape GFRP profiles by means of a gusset bolted plate placed between the elements. Taking into account the specific features of the material, the gusset plate design in frame structures has been adapted to the properties of pultrusion fiberglass. This configuration is significantly different from traditional configurations because stresses and deformations are transferred through a gusset plate.

\section{Materials and methods}

The main purpose of this experimental study is the influence of a monotonic concentrated load on the behavior of the joint on the gusset plate. For full-scale tests, a series of experimental samples of joints was made (Fig. 1). The elements of the compressed diagonal (length $330 \mathrm{~mm}$ ), diagonal in tension (length $430 \mathrm{~mm}$ ) and compressed top chord (length $1000 \mathrm{~mm}$ ) comprised two «L»-shape GFRP profiles of 105x105x13 mm size and the gusset plate $555 \times 350 \times 10 \mathrm{~mm}$ size. The elements were attached to the gusset plate through steel bolts and washers M14. The number of bolts was selected from the condition of ensuring the minimum load-bearing capacity for various types of failure.
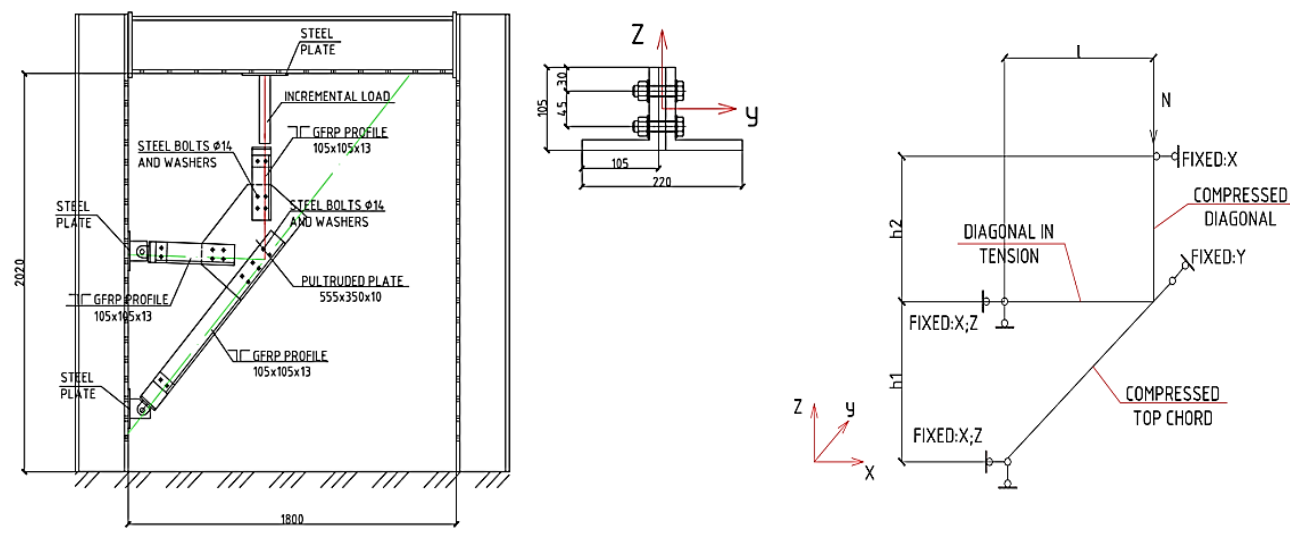

Fig. 1. Geometry and test setup (mm).

The instrumentation used for testing and evaluating the behavior of the joints consisted of 10 strain gauges, 4 displacement transducers placed as shown in Fig. 2; the displacement transducers (DC1 and DC2) were employed to measure horizontal displacement in the direction of increasing force; and other two (DC3 and DC4) to measure the horizontal and 
vertical displacement of the gusset plate. The strain gauges placed around the bolts and on the plate were oriented according to the vertical and horizontal axes to check the state of plane stress as the load increased.
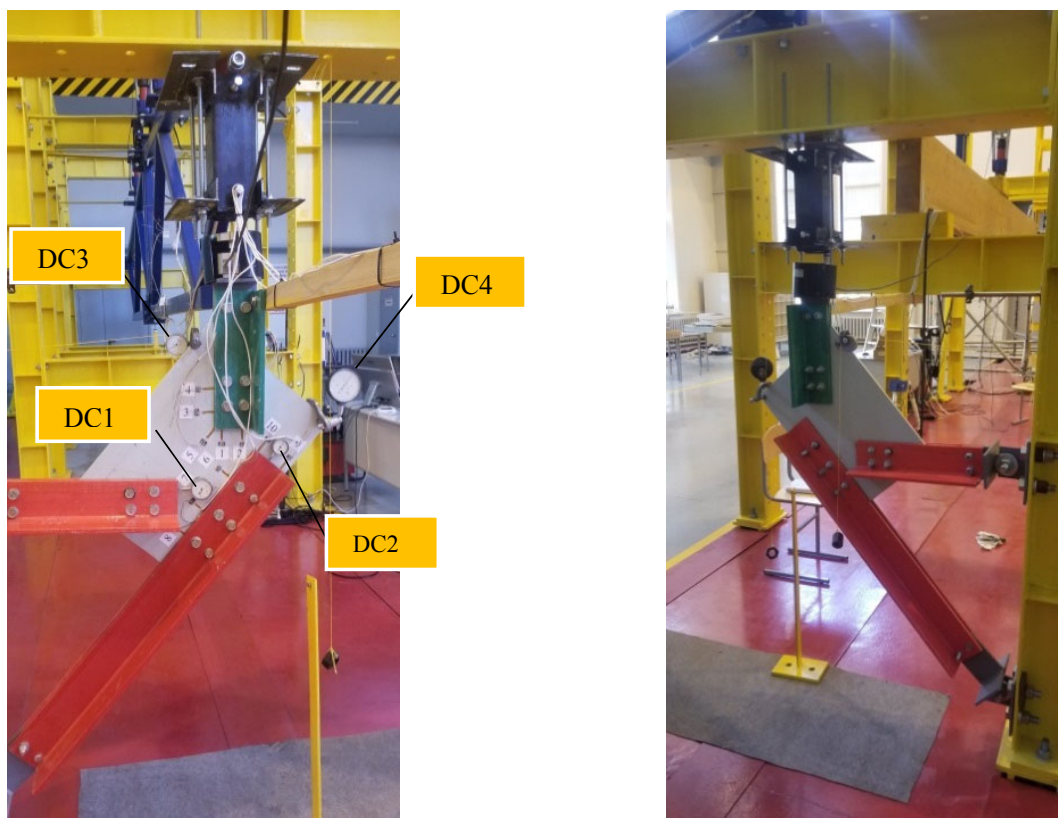

Fig. 2. Location of instrumentation.

Mechanical properties of the GFRP plates and profiles are shown in Table 1.

Table 1. Mechanical Properties of GFRP Pultruded Profiles of 105x105x13 mm and Plates.

\begin{tabular}{|l|c|c|}
\hline \multicolumn{1}{|c|}{ Property } & Notation & Value \\
\hline Longitudinal tensile modulus of elasticity & $E_{x}$ & $28(\mathrm{GPa})$ \\
\hline Transverse tensile modulus of elasticity & $E_{y}=E_{z}$ & $8.5(\mathrm{GPa})$ \\
\hline Transverse shear modulus of elasticity & $G_{y z}$ & $3(\mathrm{GPa})$ \\
\hline In-plane shear modulus of elasticity & $G_{x y}=G_{x z}$ & $3(\mathrm{GPa})$ \\
\hline Major Poisson's ratio & $v_{x y}=v_{x z}$ & 0.23 \\
\hline Major Poisson's ratio & $v_{y z}$ & 0.1 \\
\hline Bulk weight density of FRP & $\gamma$ & $1850\left(\mathrm{~kg} / \mathrm{m}^{3}\right)$ \\
\hline Longitudinal tensile strength & $\sigma_{x t}$ & $380(\mathrm{MPa})$ \\
\hline Transverse tensile strength & $\sigma_{y t}=\sigma_{z t}$ & $50(\mathrm{MPa})$ \\
\hline Longitudinal compressive strength & $\sigma_{x c}$ & $270(\mathrm{MPa})$ \\
\hline Transverse compressive strength & $\sigma_{y c}=\sigma_{z c}$ & $150(\mathrm{MPa})$ \\
\hline Shear strength & $\tau_{x y}=\tau_{x z}=\tau_{y z}$ & $25(\mathrm{MPa})$ \\
\hline
\end{tabular}

In order to determine the stress and strain state of the gusset plate a computer simulation was carried out in the ANSYS. The geometry of the node connection on the gusset plate, the location of the bolts, nuts, washers, the application of the load were modeled in the software according to the analytical calculation (Fig.3). The contact zones between the elements and the gusset plate were modeled by a «Frictional» contact. This type of contact involves the perception of the shear force between the two contacting surfaces until it reaches a certain value, after which they slip relative to each other. The value of the shear 
force is proportional to the coefficient of friction, assumed in our case to be equal to 0.1 . The contact zones of steel bolts with the elements and the gusset plate were modeled by a «Frictional» type contact.

ANSYS Composite PrepPost (ACP) is an additional utility of ANSYS Workbench, an integrated utility with the standards of analysis features. The entire workflow of the composite from design to the final product can be performed in the ACP. ACP has two modes: preprocessing and post-processing. In the preprocessing mode, a composite material is created and mapped to the geometry. The data from the preprocessing is transferred to the FE model and the calculation is performed. In the post-processing mode, after the calculations are completed, stresses, deformations and various types of failure criteria can be analyzed and visualized.
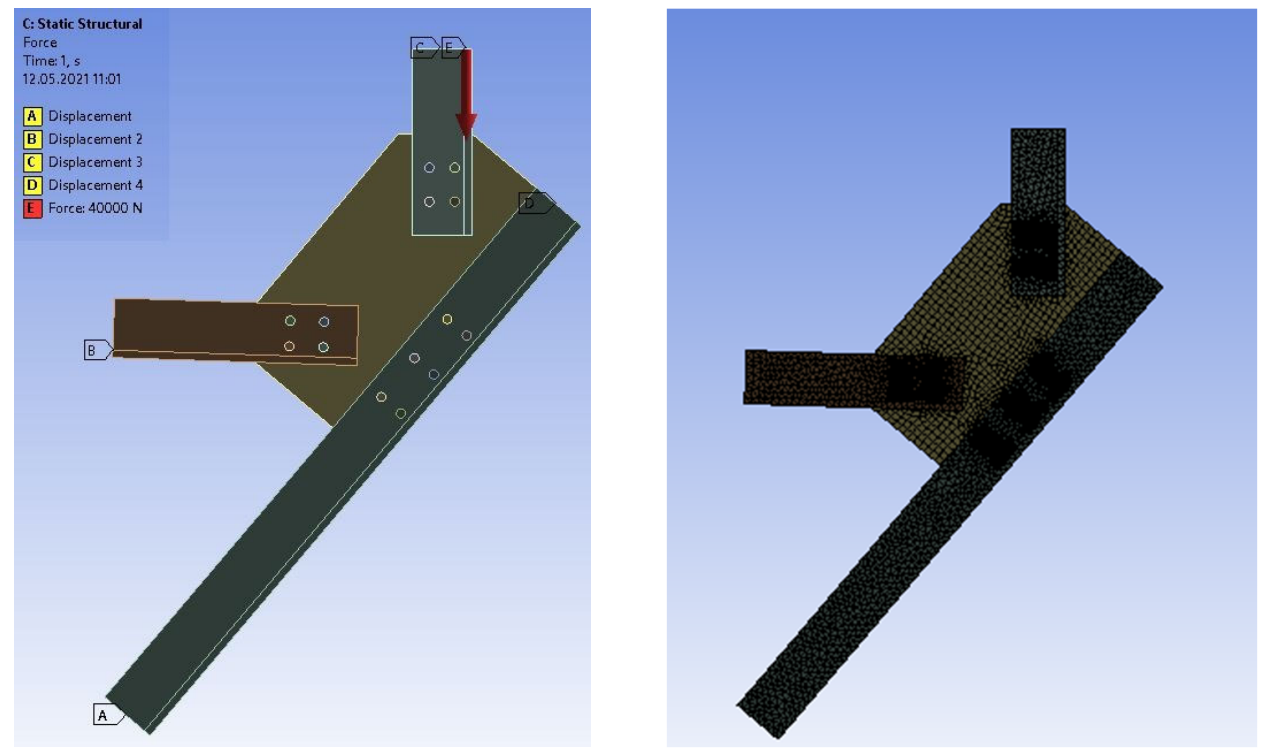

Fig. 3. Design scheme and splitting into FE.

\section{Results and discussion}

The essence of the full-scale tests was to load the joint assembly with a concentrated load applied to the compressed diagonal through a steel plate until it was destroyed. According to preliminary calculations, the destruction of the connection node should have started at a load of $22 \mathrm{kN}$. The destruction of the joint in the experiment occurred at a load of $27 \mathrm{kN}$ due to the loss of local stability of the gusset plate. It is important to note that the damage was observed in the gusset plate, while the profiles were in working condition. To a large extent, the work of the joint depended on the gusset plate. Displacement transducers that monitored any vertical or horizontal deviation recorded maximum vertical displacements of approximately $4 \mathrm{~mm}$, horizontal displacements of approximately $1 \mathrm{~mm}$.

In accordance with the applied load pattern, close to strain gauges $1 \div 5$, the profile was under compression stresses in the direction of pultrusion and perpendicular to the longitudinal axis. The strain gauges $6 \div 10$ were subjected to tension stresses in the direction of pultrusion and perpendicular to the longitudinal axis. The monitored state of stress in the profiles was less than the ultimate strength of the material.

Progressive failure analysis uses a failure criterion to predict when the material failure initiates and then reduces the stiffness of the failed material to simulate failure progress 
through the structure. Different failure criteria have been used in the literature for determining the failure of composite elements. The most famous criteria are maximum stress and maximum strain because they are simple to apply and, more significantly, they describe the mode of failure.

In ANSYS damage evolution is assumed to be an instant stiffness reduction on the basis of the reduction factor for tensile and compressive stiffness in both tension and compression. This value can range from 0 (no damage) to 1 (complete damage). The results refer to a stiffness reduction factor of 0.9 (Fig. 4).

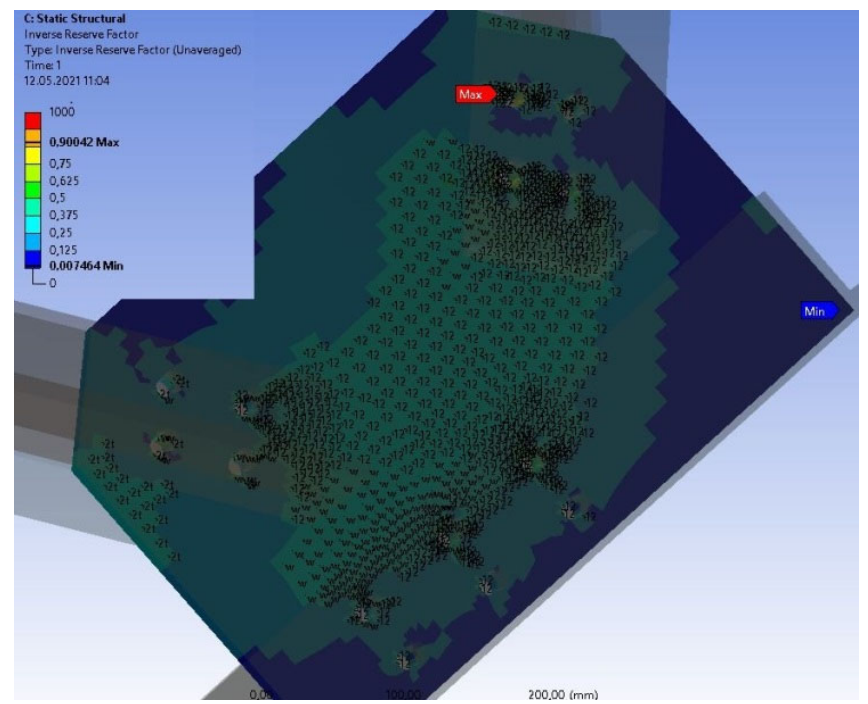

Fig. 4. Inverse Reserve Factor of gusset plate.

\section{Conclusions}

1. In this paper, an experimental and numerical study of the behaviour of bolted joints through a GFRP pultruded plate was presented. Experimental and numerical results showed that the global behaviour of the connection was substantially influenced by damage progression in the GFRP pultruded plate.

2. Instruments used during the experimental tests confirmed that the global behaviour of the joints was not influenced by the stiffness of pultruded profiles.

3. For bolted connections between pultruded profiles, the use of a GFRP pultruded plate placed between the elements, is certainly a novelty and leads to the discovery of new mechanism of failure.

\section{References}

1. A. G. Makukhin, G. V. Sirovoy, A. U. Ratushnyak, Pultrusion as a technological process for manufacturing products from composite materials, Advanced engineering technologies and systems, 1, 99-106 (2016)

2. V. A. Utkin, O. V. Solovey, Modern problems and directions of development of construction of bridges made of fiberglass materials, in collection of scientific papers of the II International scientific and practical conference of students, postgraduates and young scientists, 397-403, Omsk, Russia (2018) 
3. S. B. Singh, Chawla Himanshu, An investigation of material characterization of pultruded FRP $H$ and I-beams, Mechanics of Advanced Materials and Structures, 25, 2, 124-142 (2018) DOI: 10.1080/15376494.2016.1250021

4. F. Minghini, N. Tullini, F. Laudiero, Identification of the short-term full-section moduli of pultruded FRP profiles using bending tests, Journal of Composites for Construction, 18, 1, 1-9 (2014) DOI: 10.1061/(ASCE)CC.1943-5614.0000391

5. I. L. Kuznetsov, A. E. Fakhrutdinov, D. N. Aripov, Bolted joint in pultruded glass-reinforced plastic (GRP) profile framings, Izvestija KGASU, 4(46), 200-207 (2018)

6. I. L. Kuznetsov, M. A. Salakhutdinov, A. E. Fakhrutdinov, D. N. Aripov, Development and experimental studies structures of the canopy over the stands from pultruded glass fiber reinforced profiles. News of higher educational institutions. Construction, 9, 96-108 (2019) DOI: 10.32683/0536-1052-2019-729-9-96-108

7. R. A. Kayumov, A. A. Sharafutdinov, On the assessment of durability of building structures made of fiberglass, Izvestija KGASU, 2(40), 114-123 (2017)

8. A. E. Fakhrutdinov, D. N. Aripov, Framing structures from pultruded GRP profiles, in dig. of articles of II All Russian scientific and technical conference «Polymer composite materials and new generation production technologies», Moscow, Russia, 281-294 (2017)

9. I. L. Kuznetsov, A. E. Fakhrutdinov, D. N. Aripov, A study of bolted joints pultruded GRP profiles elements, in dig. of art. of All Russian scientific and technical conference «Polymer composite materials of new generation. Transfer of innovations from aviation to priority sectors of the Russian economy», Ul'yanovsk, Russia, 6-15 (2018)

10. Guidelines: Design and calculation of building structures made of pultruded FRP manufacturing LLC «Tatneft-Presscomposite». Central research Institute of building structures named after V. A. Kucherenko, 49, Moscow, Russia (2016)

11. L. C. Bank. Flexural and shear moduli of full-section fiber reinforced plastic (FRP) pultruded beams. J. Test. Eval, 17, 1, 40-45 (1989) DOI: 10.1520/JTE11531J

12. A. S. Neto, H. L. Rovere, Flexural stiffness characterization of fiber reinforced plastic (FRP) pultruded beams, Compos. Struct., 81, 2, 274-282 (2007) DOI: 10.1016/j.compstruct.2006.08.016

13. R. J. Brooks, G. J. Turvey, Lateral buckling of pultruded GRP I-section cantilevers, Compos. Struct., 32, 1-4, 203-215 (1995)

14. T. M. Roberts, H. Al-Ubaidi, Flexural and torsional properties of pultruded fiber reinforced plastic I-Profiles, J.Compos. Constr., 6, 1, 28-34 (2002) DOI: 10.1061/(ASCE)10900268(2002)6:1(28)

15. I. L. Howard, Practical approaches for evaluating bending and torsion of fiber-reinforced polymer components using instrumented testing, J. Appl. Sci. Eng. Tech., 2, 1, 24-30 (2008)

16. F. Minghini, N. Tullini and F. Lauderio, Full section properties of pultruded FRP profiles using bending tests, in Proceedings of the $6^{\text {th }}$ Int. Conference on FRP Composites in Civil Engineering, 1-8, Rome (2012)

17. M. M. Correia, Structural behavior of pultruded GFRP profiles experimental study and numerical modeling, Inst. Superior Tech, 1, 1-14 (2012) DOI: 10.1016/j.tws.2016.05.004

18. J. R. Correia, F. A. Branco, N. M. F. Silva, D. Camotim, N. Silvestre, First-order, buckling and post-buckling behavior of GFRP pultruded beams. Part 1: Experimental study, Comput. Struct., 89, 21-22, 2052-2064 (2011)

19. B. A. K. Maji, R. Acree, D. Satpathi, K. Donelly, Evaluation of pultruded FRP composites for structural applications, J. Mat. Civil. Eng, 9, 3, 154-158 (1997) DOI: 10.1061/(asce)08991561(1997)9:3(154)

20. P. Feraboli, K. T. Kedward, Four-point bend interlaminar shear testing of uni- and multidirectional carbon/epoxy composite systems, Compos. A, 34, 12, 1265-1271 (2003) DOI: 10.1016/S1359-835X(03)00204-5 